\title{
Nipah Virus Infection: An Emerging Zoonotic Threat
}

\author{
Zahoor Ahmad War ${ }^{1 *}$, Bilal Ahmad Malla ${ }^{2}$, Aquil Mohammad ${ }^{3}$ and \\ Irshad Ahmad Para
}

\author{
${ }^{1}$ Division of Pathology, ${ }^{2}$ Division of Public Health \& Epidemiology, ${ }^{3}$ Division of \\ Parasitology, ${ }^{4}$ Division of Physiology \& Climatology, Indian Veterinary Research Institute, \\ Izatnagar Bareilly, UP-243122, India
}

*Corresponding author

\begin{abstract}
A B S T R A C T
Keywords

Nipah virus, Encephalitis, Zoonotic disease,

Outbreaks, Pteropid bats

Article Info

Accepted:

22 October 2018

Available Online:

10 November 2018

Nipah virus is an emerging zoonotic paramyxovirus that causes severe and often fatal disease in pigs and humans. The natural host of the virus is fruit bats of the Family Pteropodidae. The virus spreads through direct contact with infected bats, pigs, or from other infected people. After an incubation period of two weeks, the disease presents as fever, headache, dizziness and vomiting, followed by drowsiness, disorientation and mental confusion. Nipah virus is endemic in Southeast Asia and was first reported in Malaysia in 1999. It is a fast-spreading viral infection and caused some disastrous outbreaks in Malaysia, Bangladesh and India. The virus is very fatal having mortality rate of around $70 \%$. Regular outbreaks of Nipah Virus have been reported from Bangladesh since 2001 to 2015. The latest outbreak of Nipah virus has been recorded in May, 2018 from Kerala, India which resulted in the death of 17 individuals. Due to lack of vaccines and effective antivirals, Nipah encephalitis poses a great threat to public health.
\end{abstract}

\section{Introduction}

Emerging zoonoses are the product of socioeconomic and anthropogenic environmental changes. Increasing animalhuman interactions due to the fast-growing human population, combined with changing environmental conditions and inadequate sanitation and regulation leads to the emergence of new diseases including the zoonotic ones. Controlling zoonoses is particularly important in developing countries, where the absolute burden of these diseases is up to 130 times greater than in developed countries (Grace et al., 2012).
Expansion of road networks, development of agricultural land, and intensification of wildlife trade have caused novel pathogens to emerge from wildlife, Nipah virus is one of the best examples of the emerging zoonoses (Daszak et al., 2012).

\section{Nipah virus}

Nipah virus is a negative-sense singlestranded RNA virus. It is an enveloped virus and is pleomorphic in shape (Wang et al., 2013; Goldsmith et al., 2003). It belongs to the genus Henipavirus of family Paramyxoviridae (Tan et al., 1999). Data 
available on replication, transcription, translation, and other mechanisms of Nipah virus is very limited because it is a newly emerging virus, and also high containment facility is required for its study. Unlike other Paramyxoviruses Nipah virus does not show hemagglutinin and neuraminidase activities (Mayo, 2002). It has six genes which encode for fusion protein $(F)$, glycoprotein $(\mathrm{G})$, matrix protein $(\mathrm{M})$, nucleocapsid $(\mathrm{N})$, phosphoprotein $(\mathrm{P})$, and polymerase protein (L). Phosphoprotein (P) gene encodes various important accessory proteins known as $\mathrm{C}, \mathrm{V}$, and $\mathrm{W}$ (Harcourt et al., 2000). The $\mathrm{C}$ protein plays a very important role in regulation of viral RNA synthesis and virulence factor. V and $\mathrm{W}$ proteins are crucial for virulence, and these proteins act by inhibiting the activation of an interferon-inducible promoter (Harcourt, 2005). Nipah virus is closely related with Hendra virus which also belongs to the genus Henipavirus and shows cross reactivity with it (Zhu et al., 2006).

\section{Host range and disease transmission}

Many domesticated mammals are susceptible to Nipah virus. The virus is maintained in pig populations, but other domesticated animals like goats, dogs, cats and horses appear to be incidental hosts. The Nipah virus infection is highly contagious among pigs and is spread by coughing. Humans get infected by direct contact with infected pigs. In the 1998-1999 outbreaks ninety percent of the infected people were pig farmers or had contact with pigs (Goh et al., 2000). There is circumstantial evidence of human-to-human transmission in India in 2001. Strong evidence indicative of human-to-human transmission of the virus was found in Bangladesh in 2004 (Gurley et al., 2007). During the outbreak in Siliguri, 33 health workers and hospital visitors became ill after exposure to patients hospitalized with Nipah virus illness, suggesting nosocomial infection (Chadha et al., 2006).
The main reservoir hosts for Nipah virus are fruit bats of the genus Pteropus (flying foxes) and $P$. giganteus is thought to be an important host in Bangladesh and India and possibly other locations (Yob et al., 2001). Infected bats shed virus in their excretion and secretion such as saliva, urine, semen and excreta but they are symptomless carriers. There is strong evidence that emergence of bat-related viral infection communicable to humans and animals have been attributed to the loss of natural habitats of bats. As the flying fox habitat is destroyed by human activity the bats get stressed and hungry, their immune system gets weaker, their virus load goes up and a lot of virus spills out in their urine and saliva. During the Bangladesh outbreak the virus is suggested to have been transmitted either directly or indirectly from infected bats to humans. Drinking of fresh date palm sap, possibly contaminated by fruit bats ( $P$. giganteus) during the winter season, may have been responsible for indirect transmission of Nipah virus to humans (Luby et al., 2006).

\section{Epidemiology}

Nipah virus might be endemic across much of Southeast Asia; however, confirmed cases in humans and/or domesticated animals have only been reported in Malaysia, Bangladesh and nearby areas of northern India. It was in Malaysia in 1999 that the virus crossed the species barrier from bats to pigs and then infected humans, inducing encephalitis with upto $40 \%$ mortality (Mudie et al., 2011). The outbreak was attributed to pigs consuming fruits partially eaten by fruit bats, and transmission of infection to humans. Similar outbreaks were reported in Singapore and Bangladesh (Ling, 1999). Outbreaks in Bangladesh were different due to lack of intermediate animal hosts i.e. pig and the infection was attributed to the consumption of fruits partly eaten by bats. 
In India the Nipah virus infection was first reported in 2001 when an outbreak took place in Siliguri, near the northern border of Bangladesh. The patients affected by this outbreak presented with both encephalitis and respiratory symptoms and the case fatality rate was 68\%. After 2001, the second outbreak was reported in Nadia district of West Bengal in 2007. The cases presented mainly with fever, headache and bodyache with a few cases having episodes of vomiting, disorientation, respiratory distress and the case fatality rate was $100 \%$ (Krishnan, 2007). The infection was not reported since 2007 until the recent outbreak which started in the month of May 2018. This outbreak seems to be a reemergence of the Nipah virus in India. The epicenter of the third outbreak in India is Southern state of Kerala, Kozhikode district. The case fatality rate reaching up to $45.7 \%$ (Hariharan, 2018). The source was found to be a well which was housed with several bats from where the family was drawing water (Xinhua, 2018).

\section{Pathogenesis}

\section{Nipah virus disease in humans}

Nipah virus mainly affects nervous system, however respiratory infection has also been reported. The incubation time for Nipah virus disease is 14 days and time from onset of symptoms to death in fatal cases is approximately 16 days (Chong et al., 2002). Neurological signs of disease progress over time and result in coma, and ultimately death in severe cases. During the Nipah virus outbreak in Malaysia and Singapore patients generally presented with fever and altered mental status or decreased consciousness (Goh et al., 2000).

Magnetic resonance imaging during the acute as well as during later phases of illness revealed focal lesions disseminated throughout the brain, mainly in the subcortical and deep white matter of the cerebral hemispheres (Sarji et al., 2000). Respiratory involvement causes difficulty in breathing and mechanical ventilation was required in most of the severe cases (Chua et al., 1999). Nipah virus was isolated from throat swabs, nose swabs, urine, tracheal secretions, and CSF collected from patients and the presence of virus in CSF was correlated with poor prognosis (Chua et al., 2000) (Table 1).

Histologic changes are mainly observed in the central nervous system of patients, followed by lungs and spleen, and incidentally heart or kidneys. The main observed lesion is vasculitis of small blood vessels and capillaries, characterized by segmental endothelial destruction, mural necrosis, and karyorrhexis.

In the CNS, lesions are observed in blood vessels of the grey and white matter and viral inclusions are detected in neurons. In the lungs, besides vasculitis, alveolar hemorrhage, pulmonary edema, and aspiration pneumonia are often observed. There is no vasculitis in the spleen; rather, white pulp depletion and acute necrotizing inflammation is observed (Wong et al., 2002).

\section{Nipah virus disease in pigs}

In pigs, Nipah virus disease pathology depends on age of the animal. Adult boars and sows show mainly neurological disease, whereas pigs under 6 months of age mainly suffer from respiratory disease.

The post-mortem findings due to Nipah virus infection in pigs are relatively non-specific. The lung and the meninges are the key organs affected. The majority of the cases show mild to severe lung lesions with varying degrees of consolidation, emphysema and petechial to ecchymotic haemorrhages, and blood-tinged exudates in the airways. 
Table.1 Morbidity and mortality in humans due to Nipah virus infection

\begin{tabular}{lllllll} 
S. No & Year/Month & Country & Location & $\begin{array}{l}\text { No. of } \\
\text { cases }\end{array}$ & $\begin{array}{l}\text { No. of } \\
\text { deaths }\end{array}$ & $\begin{array}{l}\text { Case fatality } \\
\text { rate, } \%\end{array}$ \\
\hline 1 & Sep 1998-April 1999 & Malaysia & Perak, Selangor, Negeri Sembilan states & 265 & 105 & 39.6 \\
\hline 2 & Mar-1999 & Singapore & Singapore & 11 & 1 & 9 \\
\hline 3 & Jan-Feb 2001 & India & Siliguri & 66 & 45 & 68.2 \\
\hline 4 & Apr-May 2001 & Bangladesh & Meherpur & 13 & 9 & 69.2 \\
\hline 5 & Jan 2003 & Bangladesh & Naogaon & 12 & 8 & 66.7 \\
\hline 6 & Jan-Apr 2004 & Bangladesh & Rajbari, Faridpur & 67 & 50 & 74.6 \\
\hline 7 & Jan-Mar 2005 & Bangladesh & Tangail & 12 & 11 & 91.7 \\
\hline 8 & Jan-Apr 2007 & Bangladesh & Kushtia, Naogaon, Natore, Pabna, Thakurgaon & 18 & 9 & 50 \\
\hline 9 & Apr 2007 & India & Nadia & 5 & 5 & 100 \\
\hline 10 & Feb-Apr 2008 & Bangladesh & Manikganj, Rajbari & 11 & 9 & 81.8 \\
\hline 11 & Jan 2009 & Bangladesh & Gaibandha, Nilphamari, Rangpur, Rajbari & 4 & 1 & 25 \\
\hline 12 & Feb-Mar 2010 & Bangladesh & Faridpur, Gopalganj, Kurigram, Rajbari & 17 & 15 & 88.2 \\
\hline 13 & Jan-Feb 2011 & Bangladesh & Comilla, Dinajpur, Faridpur, Lalmohirhat, Nilphamari, & 44 & 40 & 90.9 \\
\hline 14 & Jan 2012 & Bangladesh & Joypurhat & 12 & 10 & 83.3 \\
\hline 15 & Jan-Apr 2013 & Bangladesh & Gaibandha, Manikganj, Naogaon, Natore, Pabna, & 24 & 21 & 87.5 \\
\hline 16 & Jan-Feb 2014 & Bangladesh & 13 districts & 18 & 9 & 50 \\
\hline 17 & Mar-May 2014 & Philippines & Philippines & 17 & 9 & 52.9 \\
\hline 18 & Jan-Feb 2015 & Bangladesh & Faridpur, Magura, Naogaon, Nilphamari, Ponchoghor, Rajbari & 9 & 6 & 66.7 \\
\hline 19 & 2018 May & India & Kozhikode and Malappuram & 18 & 17 & 94.4 \\
\hline & Total & & & 643 & 380 & 59 \\
\hline & & & & $($ WHO, 2018) \\
\hline
\end{tabular}

On cut surface, the interlobular septa are distended. The meninges show generalized congestion and oedema. Other visceral organs were apparently normal.

Histologically, pigs develop moderate to severe interstitial pneumonia. Like in human Nipah virus infections, pigs develop widespread vasculitis in lungs, brain, and kidneys. In the brain, nonsuppurative meningitis with gliosis is observed (Mohd et al., 2000). Experimental infection in pigs has shown that Nipah virus reaches the CNS via transport along cranial nerves as well as by crossing the blood-brain barrier (Weingartl et al., 2005).

\section{Clinical symptoms}

Clinical symptoms of Nipah virus infection vary from the asymptomatic to very severe. During surveillance studies in Malaysia, 27\% pig farmer families were asymptomatic (Parashar et al., 2000). Nipah virus infection in humans produces an encephalitic syndrome which is primarily characterized by headache, pyrexia, and other neurological symptoms. Fever was found to be universal symptom followed by headache in $65 \%$ to $88 \%$ of patients (Wong et al., 2001). Apart from fever, other symptoms like vomiting, dizziness, brain stem abnormalities, reduced or absent reflexes, and doll's- eye reflexes are 
also observed frequently during Nipah virus outbreak (ICDDR, 2004). The respiratory symptoms are second most common after neurological symptoms in Nipah virus infection. Cough, cold, and dyspnea are most common respiratory symptoms reported, while abdominal pain, diarrhea, gastritis, and constipation have also been reported in few cases (Luby et al., 2006).

\section{Diagnosis}

\section{Presumptive diagnosis on-farm}

Necropsies should be conducted of recently dead and acutely diseased pigs. Animals chosen should be representative of the affected ages and types, and should include a number of animals to increase the sensitivity of the sampling procedure. There are no pathognomonic features ascribable to Nipah virus disease in pigs. Differential diagnoses should include Classical swine fever, Porcine reproductive and respiratory syndrome, Aujeszky's disease, Porcine pleuropneumonia and Pasteurellosis. Severe respiratory symptoms, neurological symptoms, or increased mortalities in sows may help in differential diagnosis.

\section{Confirmatory laboratory diagnosis}

Procedures for the laboratory diagnosis of Nipah virus infections include serology, histopathology, immunohistochemistry, electron microscopy, polymerase chain reaction (PCR), and virus isolation. The recommended initial screening tests are ELISA serology and immunohistochemistry, neither of which amplify infectious virus, and so are safer tests in the laboratory.

\section{Prevention and Control}

There is no effective treatment for Nipah virus disease, but ribavarin may alleviate the symptoms of nausea, vomiting, and convulsions (Chong et al., 2001). Treatment is mostly focused on managing fever and the neurological symptoms. Severely ill individuals need to be hospitalized and may require the use of a ventilator. Human-tohuman transmission of the virus has been reported in recent outbreaks demonstrating a risk of transmission of the virus from infected patients to healthcare workers through contact with infected secretions, excretions, blood or tissues. Healthcare workers caring for patients with suspected or confirmed Nipah virus infection should implement Standard Precautions when caring for patients and handling specimens from them.

Establishing appropriate surveillance systems will be necessary so that Nipah virus outbreaks can be detected quickly and appropriate control measures initiated. There is a need to inspect all the imported livestock at the point of origin and when they arrive. All the facilities for their slaughter need to be maintained at the highest level of hygiene possible. It is also essential to take proper precautions for workers. For those who come down with these zoonoses, we must ensure that facilities for the care of patients are available, that all health care and veterinary care personnel have adequate protection, and that laboratories are equipped with adequate facilities to handle these dangerous organisms (Ling, 1999). There is a need to have active inter-institutional and international coordination among human-animal virologists as well as virologists and ecologists to fully understand how and when the bats excrete the virus. Simultaneously there is also a need for educating the common people about personal and food hygiene.

Nipah virus continues to cause annual outbreaks in Southeast Asia, with high case fatality rates even after the two decades of its emergence. The virus can cause large-scale human outbreaks if it gets adapted to the human-to-human transmission. Therefore, 
efforts should be focused on the intervention strategies aimed at blocking zoonotic and human-to-human transmission. The increasing contact between bats and humans as a result of habitat destruction and climate change, alarms the more zoonotic transmission events in the future. There is the need of improved communication between medical and veterinary health under 'One Health' approach (Mackenzie, 2009). The key to controlling the outbreak and reducing mortalities is early detection of the outbreak and installing preventive measures as soon as possible, because a delay or neglect can lead to an outbreak of tragic consequences.

\section{References}

Chadha MS, Comer JA, Lowe L, et al., 2006. Nipah virus- associated encephalitis outbreak, Siliguri, India. Emerg Infect Dis. 12(2):235- 240.

Chong HT, Kamarulzaman A, Tan CT, Goh KJ, Thayaparan T, Kunjapan SR, et al., 2001. Treatment of acute Nipah encephalitis with ribavirin. Ann Neurol. 49(6):810-813.

Chong HT, Kunjapan SR, Thayaparan T, Tong J, Petharunam V, et al., 2002. Nipah encephalitis outbreak in Malaysia, clinical features in patients from Seremban. Can J Neurol Sci. 29(1):83-87.

Chua KB, Goh KJ, Wong KT, Kamarulzaman A, Tan PS, et al., 1999. Fatal encephalitis due to Nipah virus among pig-farmers in Malaysia. Lancet. 354(9186): 1257-1259.

Chua KB, Lam SK, Tan CT, Hooi PS, Goh $\mathrm{KJ}$, et al., 2000. High mortality in Nipah encephalitis is associated with presence of virus in cerebrospinal fluid. Ann Neurol. 48(5): 802-805.

Daszak P. Anatomy of a pandemic. Lancet. 2012. 380(9857):1883-1884.
Goh KJ, Tan CT, Chew NK, Tan PS, Kamarulzaman A, et al., 2000. Clinical features of Nipah virus encephalitis among pig farmers in Malaysia. N Engl J Med. 342(17):1229-1235.

Goldsmith CS, Whistler T, Rollin PE, et al., 2003. Elucidation of Nipah virus morphogenesis and replication using ultrastructural and molecular approaches. Virus Res.. 92(1):89- 98.

Grace D, Mutua F, Ochungo P, Kruska R, Jones K, Brierley L, Lapar L, Said M, Herrero M, Phuc PM, Thao NB, Akuku I and Ogutu F. 2012. Mapping of poverty and likely zoonoses hotspots. Zoonoses Project 4. Report to the UK Department for International Development. Nairobi, Kenya: ILRI.

Gurley E, Montgomery JM, Hossain MJ, Bell M, Azad AK, Islam MR, et al., Personto-person transmission of Nipah virus in a Bangladeshi community. Emerg Infect Dis. 13(7):1031

Harcourt BH, Tamin A, Ksiazek TG, et al., 2000. Molecular characterization of Nipah virus, a newly emergent paramyxovirus. Virology. 271(2): 334- 349

Harcourt BH. Genetic characterization of Nipah virus, Bangladesh, 2004. 2005. Emerg Infect Dis. 11(10):1594- 1597.

Hariharan R. Fresh Nipah outbreak scare, schools, colleges to stay shut in Kozhikode till June 12: 10 points. Available at: https://www.ndtv.com/ kerala-news/kerala-warns-of-secondwave-of-nipah-virus-killed-16-10-points -1861308?pfrom=home-topstories.

International Centre for Diarrhoeal Disease Research, Bangladesh. 2004. Nipah encephalitis outbreak over wide area of Western Bangladesh, 2004. Health Sci Bull. 2:7- 11 .

Krishnan S. Nipah outbreak in India and Bangladesh. 2007. WHO 
Communicable Disease Department Newsletter. 4(2).

Ling AE. 1999. Lesson to be learnt from Nipah Virus Outbreak in Singapore. Singapore Med J. 40(05):3.

Luby SP, Rahman M, Hossain MJ, et al., 2006. Foodborne transmission of Nipah virus, Bangladesh. Emerg Infect Dis. 12(12):1888- 1894.

Mackenzie JS. 2009. Global Outbreak Alert and Response Network (GOARN) and One Health: Nipah virus as a source of lessons learnt- CDC Presentation.

Mayo MA. 2002. A summary of taxonomic changes recently approved by ICTV. Arch Virol. 147(8):1655- 1663.

Mohd Nor MN, Gan CH, Ong BL. 2000. Nipah virus infection of pigs in peninsular Malaysia. Rev Sci Tech. 19(1):160-165.

Mudie L. 2011. Breakthrough in Nipah Virus Resarch. Healthcare News.

Parashar UD, Sunn LM, Ong F, et al., 2000. Case- control study of risk factors for human infection with a new zoonotic paramyxovirus, Nipah virus, during a 1998- 1999 outbreak of severe encephalitis in Malaysia. J Infect Dis. 181(5):1755- 1759.

Sarji SA, Abdullah BJ, Goh KJ, Tan CT, Wong KT. 2000. MR imaging features of Nipah encephalitis. AJR Am J Roentgenol. 175(2):437-442.

Tan KS, Tan CT, Goh KJ. 1999. Epidemiological aspects of Nipah virus infection. Neurol J Southeast Asia. 4(1):77- 81

Wang LF, Harcourt BH, Yu M, et al., 2001. Molecular biology of Hendra and Nipah viruses. Microbes Infect. 3(4):279- 287.
Weingartl H, Czub S, Copps J, Berhane Y, Middleton D, et al., 2005. Invasion of the central nervous system in a porcine host by nipah virus. J Virol. 79(12):7528-7534.

Wong KT, Shieh WJ, Kumar S, Norain K, Abdullah W, et al., 2002. Nipah virus infection: pathology and pathogenesis of an emerging paramyxoviral zoonosis. Am J Pathol. 161(6):2153-2167.

Wong SC, Ooi $\mathrm{MH}$, Wong $\mathrm{MN}$, Tio $\mathrm{PH}$, Solomon T, Cardosa MJ. 2001. Late presentation of Nipah virus encephalitis and kinetics of the humoral immune response. J Neurol Neurosurg Psychiatry. 71(4):552- 554.

World Health Organization. Nipah virus outbreaks in the WHO South- East Asia Region. http://www.searo.who.int/ entity/emerging_diseases/links/nipah_vi rus_outbreaks sear/en/.

Xinhua. Bat infected well liked to 3rd outbreak of Nipah virus in India since 2001: officials. Asia and Pacific. Available at: http://www.xinhuanet. com/english/2018-05/23/c_137200667. html.

Yob JM, Field H, Rashdi AM, Morrissy C, van der Heide B, Rota P, bin Adzhar A, White J, Daniels P, Jamaluddin A, Ksiazek T. 2001. Nipah virus infection in bats (order Chiroptera) in peninsular Malaysia. Emerging infectious diseases. 7(3):439.

Zhu Z, Dimitrov AS, Bossart KN, et al., 2006Potent neutralization of Hendra and Nipah viruses by human monoclonal antibodies. J Virol. 80(2):891- 899 .

\section{How to cite this article:}

Zahoor Ahmad War, Bilal Ahmad Malla, Aquil Mohammad and Irshad Ahmad Para. 2018. Nipah Virus Infection: An Emerging Zoonotic Threat. Int.J.Curr.Microbiol.App.Sci. 7(11): 2963-2969. doi: https://doi.org/10.20546/ijcmas.2018.711.339 